\title{
AUDIT KINERJA SISTEM INFORMASI PENELUSURAN PERKARA PADA PENGADILAN AGAMA TANJUNG KARANG KELAS I A BANDAR LAMPUNG
}

\author{
Yusra Fernando ${ }^{1}$, Rayin Bi Ilmillah², Dedi Darwis ${ }^{3}$ \\ Sistem Informasi, Universitas Teknokrat Indonesia \\ Jl. H. ZA Pagaralam, 9-11. Labuhanratu, Bandarlampung \\ Email :yusra.fernando@teknokrat.ac.id ${ }^{l}$,ayimbiilah@gmail.com ${ }^{2}$,dedikomdat@gmail.com ${ }^{3}$
}

\begin{abstract}
Abstrak
Pengadilan Agama Tanjung Karang Kelas I A Bandar Lampung merupakan Pengadilan Agama (PA) tingkat pertama yang berkedudukan di kota Bandar Lampung dengan wilayah hukum meliputi kota Bandar Lampung dan sekitarnya, berwenang dalam perkara perdata tertentu bagi orang-orang muslim serta sebagian non muslim. PA Tanjung Karang dalam proses pengolahan data perkaranya sudah menggunakan teknologi informasi yaitu Sistem Informasi Penelusuran Perkara (SIPP). COBIT 5 merupakan sebuah kerangka yang dapat membantu organisasi atau perusahaan dalam tata pengelolaan dan manajemen TI. Audit kinerja sistem informasi menggunakan 5 domain yaitu EDM (Evaluate, Direct and Monitor), APO (Align, Plan and Organise), BAI (Build, Acqiure and Implement), DSS (Deliver, Service and Support), MEA (Monitor, Evaluate and Asses) dengan 11 proses dan 64 aktivitas yang digunakan. Kemudian dilakukan analisis data dengan menggunakan pengukuran tingkat kematangan kinerja sistem informasi yaitu Maturity Level. Audit kinerja sistem informasi memperolah hasil yaitu nilai rata-rata 3,7 dari nilai 0 sampai 5 pada domain EDM03, APO01, APO011, APO012, BAI06, DSS01, DSS02, DSS03, DSS05, MEA01 dan MEA02, artinya Pengadilan Agama Tanjung Karang Kelas I A Bandar Lampung telah memiliki sejumlah indikator atau ukuran kuantitatif yang dijadikan sebagai sasaran ataupun obyektif kinerja pada penerapan aplikasi teknologi informasi yang ada, karena organisasi memiliki kendali terhadap proses teknologi informasi untuk mengurangi variasi kinerja proses sehingga proses pengembangan dapat ditentukan dengan limit yang dapat diukur, namun harus dilakukan secara berhati-hati.
\end{abstract}

Kata kunci : COBIT 5, Audit, Kinerja dan Sistem Informasi

\section{PENDAHULUAN}

\subsection{Latar Belakang}

Perkembangan teknologi informasi pada instansi sangat penting untuk mendukung aset perusahaan, teknologi informasi juga memberikan manfaat bagi perusahaan serta digunakan untuk memberikan nilai bagi stakeholder. Perusahaan harus memahami dan mengelola risiko yang terkait, seperti meningkatnya pemenuhan akan regulasi dan ketergantungan proses bisnis pada teknologi informasi, namun masih ada beberapa perusahaan yang belum menerapkan teknologi informasi untuk kegiatan proses bisnisnya (ITGI 2007:5). Mengingat peran teknologi informasi dan komunikasi yang semakin penting bagi upaya peningkatan kualitas layanan sebagai salah satu realisasi dari tata kelola pemerintahan yang baik (Kominfo 2011:7). Untuk memastikan bahwa teknologi informasi disuatu perusahaan sudah mencapai visi dan misi perusahaan, maka perlu dilakukan audit sistem informasi terhadap teknologi informasi tersebut. Audit sistem informasi merupakan proses untuk mengatasi penggunaan teknologi baru dalam suatu perusahaan untuk memberikan evaluasi independen mengenai kegiatan proses bisnis yang dikerjakan dan dilaporkan apakah sudah sesuai dengan standar yang telah ditetapkan perusahaan (ICAI : 2010).

Pengadilan Agama Tanjung Karang Kelas I A Bandar Lampung merupakan Pengadilan Agama (PA) tingkat pertama yang berkedudukan di kota Bandar Lampung dengan wilayah hukum meliputi kota Bandar Lampung dan sekitarnya, berwenang dalam perkara perdata tertentu bagi orang-orang muslim serta sebagian non muslim. PA Tanjung Karang dalam proses pengolahan data perkaranya sudah menggunakan teknologi informasi yaitu Sistem Informasi Penelusuran Perkara (SIPP).. SIPP merupakan sistem yang baru berjalan sekitar 2 tahun sehingga belum dilakukan audit terhadap sistem apakah kinerja SIPP telah mencapai visi dan misi PA Tanjung Karang, data perkara pada aplikasi SIPP harus di kirim ke pusat untuk dilakukan monitoring terhadap data, untuk memastikan bahwa data yang di kirim terjamin kerahasiaannya dan keamanannya, untuk itu diperlukan audit kinerja sistem informasi untuk mengendalikan dan memastikan bahwa SIPP sudah sesuai dengan tujuan PA Tanjung Karang. Untuk mengantisipasi kebutuhan yang dibatasi oleh waktu sehingga kinerja sistem harus berjalan dengan cepat agar menghasilkan hasil yang sesuai dengan tujuannya maka harus dilakukan audit sistem informasi. Audit sistem 
informasi ini menggunakan framework COBIT 5 (Control Objectives for Information and Related Technology).

COBIT 5 menyediakan kerangka kerja yang komprehensif serta dasar yang kuat untuk keamanan informasi yang membantu perusahaan untuk mencapai tujuan dan memberikan nilai melalui tata kelola dan manajemen perusahaan IT yang efektif. Kerangka COBIT 5 merupakan sebuah kerangka yang dapat membantu organisasi atau perusahaam dalam tata pengelolaan dan managemen TI (ISACA 2012 dan Solehah 2016).

\subsection{Rumusan Masalah}

1. Bagaimana menganalisis kinerja sistem informasi penelusuran perkara dengan menggunakan framework COBIT 5 dengan domain proses EDM03, APO01, APO011, APO012, BAI06, DSS01, DSS02, DSS03, DSS05, MEA01, dan MEA02 pada Pengadilan Agama Tanjung Karang Kelas I A Bandar Lampung?

2. Bagaimana hasil evaluasi analisis kinerja sistem informasi menggunakan framework COBIT 5 dengan domain EDM (Evaluate, Direct and Monitor), APO (Align, Plan and Organise), BAI (Build, Acqiure and Implement), DSS (Deliver, Service and Support), dan MEA (Monitor, Evaluate and Asses) pada Pengadilan Agama Tanjung Karang Kelas I A Bandar Lampung?

\subsection{Tujuan}

Tujuan dari penelitian ini adalah sebagai berikut :

1. Menganalisis kinerja Sistem Informasi Penelusuran Perkara dengan menggunakan framework COBIT 5 dengan domain proses EDM03, APO01, APO011, APO012, BAI06, DSS01, DSS02, DSS03, DSS05, MEA01, dan MEA02 pada Pengadilan Agama Tanjung Karang Kelas I A Bandar Lampung.

2. Hasil evaluasi analisis kinerja sistem informasi penelusuran perkara menggunakan framework COBIT 5 dengan domain EDM (Evaluate, Direct and Monitor), APO (Align, Plan and Organise), BAI (Build, Acqiure and Implement), DSS (Deliver, Service and Support), dan MEA (Monitor, Evaluate and Asses) pada Pengadilan Agama Tanjung Karang Kelas I A Bandar Lampung.

\subsection{Metodologi}

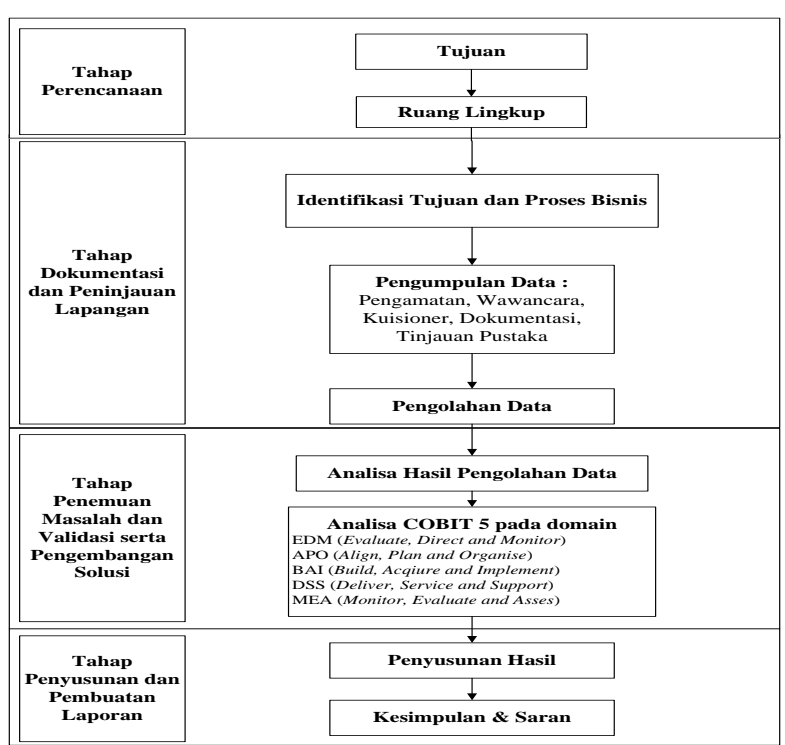

Gambar 1. Kerangka Pemikiran

\subsection{Tinjauan Pustaka}

Tinjauan pustaka yang digunakan oleh penulis (no literatur; penulis; tahun; dan judul) yaitu :

1. 001; Ariel Bagus Nugroho, Amiq Fahmi; 2015; Analisis Tingkat Kapabilitas Sistem Informasi Rumah Sakit Berdasarkan COBIT 5 (MEA01) pada RSUD Tugurejo Semarang

2. 002; Christina Juliane, Rakhmayudhi, Nuraeni; 2014; Pengukuran Kinerja Sistem Informasi di PT. Rancek Sukses Bandung dengan Menggunakan Framework COBIT 5.0 (Studi Kasus SIOS-Sistem Informasi Kios)

3. 003; Beni Suranto, Farah Fauziyah Hanum, Kholid Haryono; 2014; Audit Sistem Informasi RSUD Sleman untuk Monitoring dan Evaluasi Kinerja Sistem

4. 004; Achyar Al-Rasyid; 2014; Analisis Audit Sistem Informasi Berbasis COBIT 5 pada Domain Deliver, Service, and Support (DSS) (Studi Kasus : SIM-BL di Unit CDC PT Telkom Pusat. Tbk)

5. 005; M. Ilham Nur Faizin, Eva Hariyanti, Badrus Zaman; 2015; Pembangunan Tools Audit Sistem Informasi Berdasarkan COBIT 5 pada Domain Align, Plan, and Organize (APO)

\subsection{Landasan Teori}

Pengertian Audit Menurut (Schiller : 2011) dalam bukunya mendefinisikan audit proses untuk memperbaiki keadaan teknologi informasi agar sejalan dengan tujuan perusahan. Menurut (ICAI : 2010) audit sistem informasi merupakan proses untuk mengatasi penggunaan teknologi baru dalam suatu perusahaan untuk memberikan evaluasi independen mengenai kegiatan proses bisnis yang dikerjakan dan dilaporkan apakah sudah sesuai dengan standar yang telah ditetapkan perusahaan.

1. Tahapan Penelitian Audit 
Menurut (Schiller : 2011) proses audit sistem informasi dilakukan melalui tahapantahapan sebagai berikut :

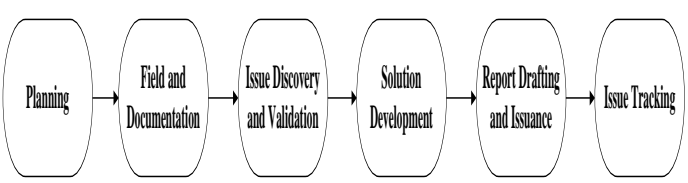

Gambar 2. Tahapan Penelitian Audit

\section{a. Planning (Perencanaan)}

Tujuan dari proses perencanaan adalah menentukan tujuan dan ruang lingkup audit. Penulis perlu menentukan apa yang akan dicapai dari hasil pengauditan.

b. Field and Documentation (Dokumentasi dan Peninjauan Lapangan)

Dokumentasi merupakan bagian penting dari sebuah penelitian audit. Penulis harus bekerja secara maksimal untuk mendokumentasikan pekerjaan penulis, sehingga dapat diinformasikan kepada orang lain dan dapat dipahami apa yang penulis lakukan dan untuk memperkuat kesimpulan yang penulis buat.

c. Issue Discovery and Validation (Penemuan Masalah dan Validasi) Penulis yang menemukan sebuah permasalahan harus memvalidasi permasalahan tersebut. Karena permasalahan yang akan diaudit harus memiliki fakta yang benar, tidak mengangkat isu-isu karena menyajikan isuisu akan memunculkan risiko yang besar bagi perusahaan..

\section{d. Solution Development (Pengembangan}

\section{Solusi)}

Setelah penulis melakukan identfikasi masalah dan telah divalidasi fakta dan risikonya, penulis dapat bekerja sama dengan pengguna sistem untuk mengembangkan rencana selanjutnya untuk mengatasi setiap permasalahan yang ada. Penulis dapat memberikan rekomendasi untuk menangani permasalahan yang terjadi, kemudian penulis meminta pengguna sistem untuk melihat rekomendasi yang mungkin akan mereka setujui.

e. Report Drafting and Issuance

(Penyusunan dan Pembuatan Laporan)

Penting bagi penulis untuk membuat laporan agar menghindari kesalah pahaman. Meringkas semua masalah secara rinci, penulis perlu menulis ringkasan sehingga seseorang tidak membuang banyak waktu untuk membaca semua detail laporan agar dapat memahami kondisi keseluruhan dari hasil audit.

f. Issue Tracking (Pematangan Masalah)
Penulis harus mengembangkan proses audit, karena dimasa yang akan datang dapat dilacak dan diikuti oleh peneliti setelahnya.

2. Pengertian Framework COBIT 5

ISACA (2012) COBIT 5 (Control Objectives For Information and Related Technology) merupakan generasi dari panduan ISACA dibuat berdasarkan pengalaman penggunaan COBIT selama lebih dari 15 tahun oleh banyak perusahaan dan penggunaan dari bidang bisnis, komunitas, IT, risiko, asuransi, dan keamanan. COBIT 5 mendefinisikan dan menjelaskan secara rinci sejumlah tata kelola dan manajemen proses. COBIT 5 menyediakan kerangka kerja yang komprehensif yang membantu perusahaan dalam mencapai tujuan mereka untuk tata kelola dan manajemen aset informasi perusahaan dan teknologi (IT). Secara sederhana, membantu perusahaan menciptakan nilai yang optimal dari IT dengan menjaga keseimbangan antara mewujudkan manfaat dan mengoptimalkan tingkat risiko dan penggunaan sumber daya. (ISACA 2012).

COBIT 5, memiliki kriteria informasi asli sbb :

a. Efisiensi

b. Efektivitas

c. Kerahasiaan

d. Integritas

e. Ketersediaan

f. Kepatuhan

g. Kehandalan

3. Domain Framework COBIT 5

Berdasarkan penjelasan pada jurnal ISACA tahun 2012, COBIT 5 framework dirancang dengan 5 domain yang masing-masing mencakup penjelasan rinci dan termasuk panduan secara luas dan bertujuan sebagai tata kelola dan manajemen TI perusahaan.

Terdapat 5 (lima) domain yang ada pada COBIT 5 adalah :

a. EDM (Evaluate, Direct, and Monitor) Mengevaluasi, Mengarahkan dan Memantau

Proses tata kelola ini berkaitan dengan tujuan tata kelola pemangku kepentingan dalam melakukan penelitian, optimasi risiko dan sumber daya, mencakup praktek dan kegiatan yang bertujuan untuk mengevaluasi pilihan strategis, memberikan arahan kepada TI dan pemantasan hasilnya EDM terdiri dari 5 subdomain proses yaitu :

1. EDM01 : Memastikan Penetapan Kerangka Kerja Tata Kelola dan Pemeliharaan

2. EDM02 : Memastikan Penyampaian Keuntungan

3. EDM03 : Memastikan Optimasi Risiko

4. EDM04 : Memastikan Optimasi Sumber Daya

5. EDM05 : Memastikan Tranparasi Pemangku Kepentingan 
b. APO (Align, Plan and Organise) Menyelaraskan, Rencana dan Mengorganisir

Domain ini mencakup strategi dan taktik, serta mengidentifikasi kekhawatiran cara terbaik TI agar dapat berkontribusi pada pencapaian tujuan bisnis. Pada domain APO terdapat $13 \mathrm{sub}$ domain proses yaitu :

1. APO01: Mengelola Kerangka Kerja Manajemen TI

2. APO02 : Mengelola Strategi

3. APO03 : Mengelola Arsitektur Perusahaan

4. APO04 : Mengelola Inovasi

5. APO05 : Mengelola Portofolio

6. APO06 : Mengelola Anggaran dan Biaya

7. APO07 : Mengelola Sumber Daya Manusia

8. APO08 : Mengelola Hubungan

9. APO09 : Mengelola Perjanjian Layanan

10. APO010 : Mengelola Penyedia

11. APO011: Mengelola Kualitas

12. APO012 : Mengelola Risiko

13. APO013 : Mengelola Pelayanan

c. BAI (Build, Acquire and Implement) Membangun, Memperoleh dan Melaksanakan

Memberikan solusi dan melewatinya sehingga akan berubah menjadi layanan. Untuk mewujudkan strategi TI, solusi TI perlu diidentifikasi, dikembangkan atau diperoleh, serta diimplementasikan dan terintegrasi ke dalam proses bisnis. Domain BAI terdiri dari 10 sub domain proses yaitu :

1. BAI01 : Mengelola Program dan Proyek

2. BAI02 : Mengelola Penetapan Persyaratan

3. BAI03 : Mengelola Identifikasi Solusi dan Membangun

4. BAI04: Mengelola Ketersediaan dan Kapasitas

5. BAI05 : Mengelola Pemberdayaan Perubahan Organisasi

6. BAI06 : Mengelola Perubahan

7. BAI07 : Mengelola Penerimaan terhadap Perubahan dan Masa Transisi

8. BAI08 : Mengelola Pengetahuan

9. BAI09 : Mengelola Aset

10. BAI010 : Mengelola Konfigurasi

d. DSS (Deliver, Service and Support) Penyampaian, Layanan dan Dukungan

Meliputi mengirimkan, layanan, dan dukungan atau member pelayanan yang aktual bagi bisnis, termasuk manajemen data dan proteksi informasi yang berhubungan dengan proses bisnis. Domain DSS terdiri dari $6 \mathrm{sub}$ domain yaitu :

1. DSS01 : Mengelola Operasi

2. DSS02 : Mengelola Permintaan Layanan dan Insiden

3. DSS03 : Mengelola Masalah

4. DSS04 : Mengelola Kelangsungan

5. DSS05 : Mengelola Layanan Keamanan
6. DSS06 : Mengelola Kendali Proses Bisnis

e. MEA (Monitor, Evaluate, and Assess) Memantau, Mengevaluasi dan Menilai

Domain ini berkaitan dengan pengiriman aktual dan dukunga layanan yang dibutuhkan, yang meliputi pelayanan, pengelolaan keamanan dan kelangsungan, dukungan layanan bagi pengguna, dan manajemen data serta fasilitas operasional. Domain MEA terdiri dari 3 sub domain yaitu :

1. MEA01 : Memantau, Melakukan Evaluasi, Menilai Kinerja dan Kesesuaian

2. MEA02 : Memantau, Melakukan Evaluasi dan Menilai Sistem dari Kendali Internal

3. MEA03 : Memantau, Melakukan Evaluasi dan Menilai Kepatuhan dengan Persyaratan Internal

4. Pengukuran Tingkat Kematangan (Maturity Model)

Maturity model adalah suatu metode untuk mengukur level pengembangan manajemen proses, yang berarti adalah mengukur sejauh mana kapabilitas manajemen tersebut. Perhitungan kuisioner dilakukan dengan perhitungan berikut ini:

Mean $(\operatorname{or} \bar{X})=\frac{\sum X_{i}}{n}=\frac{X_{1}+X_{2}+\ldots+X_{n}}{n}$

(Sumber : Khotari 2004)

Dimana

$\overline{\mathrm{X}}=$ Simbol untuk mean atau rata-rata hitung

$\sum=$ Simbol untuk penjumlahan keseluruhan

$\mathrm{X}_{\mathrm{i}}=$ Nilai berapa jumlah $\mathrm{X}, \mathrm{i}=1,2, \ldots, \mathrm{n}$

$\mathrm{n}=$ Jumlah sample

Tabel 1. Level kematangan (Maturity Level)

\begin{tabular}{|l|l|}
\hline $\begin{array}{l}\text { Indek } \\
\text { Kematangan }\end{array}$ & Level Kematangan \\
\hline $0-0.49$ & $0-$ Non-Existent \\
\hline $0.50-1.49$ & $1-$ Initial/Ad Hoc \\
\hline $1.50-2.49$ & $2-$ Repeatable But Intuitive \\
\hline $2.50-3.49$ & $3-$ Defined Process \\
\hline $3.50-4.49$ & $\begin{array}{l}4-\text { Managed and } \\
\text { Measureabel }\end{array}$ \\
\hline $4.50-5.00$ & i. - Optimized \\
\hline
\end{tabular}

\section{PEMBAHASAN}

\subsection{Hasil Identifikasi Enterprise Goals}

Penulis mengelompokkan enterprise goals dari Pengadilan Agama Tanjung Karang Kelas I A Bandar Lampung, dengan enterprise goals yang ada pada COBIT 5, dengan cara melihat tujuan penelitian yaitu meningkatkan kinerja sistem informasi maka penulis mengkategorikan tujuan tersebut kedalam tujuan perusahaan (enterprise goals) yang terdapat pada COBIT 5 pada bagian Managed Bussiness Risk (Safeguarding of Assets). 
Enterprise goals termasuk dalam kategori Managed Bussiness Risk (Safeguarding of Assets).

\subsection{Hasil Identifikasi IT Related Goals}

Pada tahap ini penulis melakukan pemilihan IT Related Goals, berdasarkan perbandingan matrik dari enterprise goals. Ada tiga IT Related Goals yang memiliki hubungan yang bersifat "Primer" dengan Managed Bussiness Risk (Safeguarding of Assets) yaitu Manage IT-related business risk, Security of information, processing infrastructure and applications, Enablement and support of business process by integrating applications and technology into business process.

\subsection{Identifikasi Domain COBIT 5}

Tabel 2. Identifikasi Domain Cobit 5

\begin{tabular}{|c|c|}
\hline Domain & Proses COBTT 5 \\
\hline $\begin{array}{c}\text { Evaluate, Direct and } \\
\text { Monitor }\end{array}$ & EDM03 \\
\hline $\begin{array}{c}\text { Align, Plan and } \\
\text { Organise }\end{array}$ & $\begin{array}{c}\text { APO01, APO011, } \\
\text { APO012 }\end{array}$ \\
\hline $\begin{array}{c}\text { Build, Acquire and } \\
\text { Implement }\end{array}$ & BAI06, \\
\hline $\begin{array}{c}\text { Deliver, Service, and } \\
\text { Support }\end{array}$ & DSS01, DSS02, \\
\hline $\begin{array}{c}\text { Monitor, Evaluate and } \\
\text { Assess }\end{array}$ & MEA01, MEA02 \\
\hline
\end{tabular}

\subsection{Ringkasan Tingkat Kematangan}

Rata-rata hasil perhitungan dari proses COBIT 5 dijabarkan pada tabel 3 berikut ini.

Tabel 3. Rata-rata Tingkat Kematangan

\begin{tabular}{|c|c|c|c|c|}
\hline No & Proses & Keterangan & Nilai & Kondisi \\
\hline 1 & EDM03 & Memastikan Optimasi Risiko & 3,4 & $\begin{array}{l}\text { Defined } \\
\text { Process }\end{array}$ \\
\hline 2 & APOO1 & $\begin{array}{l}\text { Mengelola Kerangka Kerja } \\
\text { Manajemen TI }\end{array}$ & 4,0 & $\begin{array}{l}\text { Managed and } \\
\text { Measureabel }\end{array}$ \\
\hline 3 & APOO11 & Mengelola Kualitas & 3,6 & $\begin{array}{l}\text { Managed and } \\
\text { Measureabel }\end{array}$ \\
\hline 4 & APO012 & Mengelola Risiko & 3,7 & $\begin{array}{l}\text { Managed and } \\
\text { Measureabel }\end{array}$ \\
\hline 5 & BAIOE & Mengelola Perubahan & 3,9 & $\begin{array}{l}\text { Managed and } \\
\text { MeasureabeI }\end{array}$ \\
\hline 6 & DSSO1 & Mengelola Operasi & 3,5 & $\begin{array}{l}\text { Managed amd } \\
\text { Measureabel }\end{array}$ \\
\hline 7 & $\mathrm{DSSO} 2$ & $\begin{array}{l}\text { Mengelola Pemintaan Layanandan } \\
\text { Insiden }\end{array}$ & 3,8 & $\begin{array}{l}\text { Managed and } \\
\text { Measureablel }\end{array}$ \\
\hline 8 & DSSO3 & Mengelola Masalah & 3,4 & $\begin{array}{l}\text { Defined } \\
\text { Process }\end{array}$ \\
\hline 9 & DSSOS & Mengelola Layanan Keamanan & 3,5 & $\begin{array}{l}\text { Managed and } \\
\text { Measureabel }\end{array}$ \\
\hline 10 & MEAOI & $\begin{array}{l}\text { Memantan, Melakukan Evahuasi, } \\
\text { Menilai Kinerja dan Kesesuaian }\end{array}$ & 3,9 & $\begin{array}{l}\text { Managed and } \\
\text { Measureabel }\end{array}$ \\
\hline 11 & MEA02 & $\begin{array}{l}\text { Merrantan, Melakukan Evahuasidan } \\
\text { Menilai Sistem dari Kendali Intemal }\end{array}$ & 3,7 & $\begin{array}{l}\text { Managed and } \\
\text { Measureabel }\end{array}$ \\
\hline \multicolumn{3}{|r|}{ Nilai Rata-rata } & 3,7 & $\begin{array}{l}\text { Managed and } \\
\text { Measureabel }\end{array}$ \\
\hline
\end{tabular}

Pada tabel hasil perhitungan nilai kematangan menghasilkan nilai tingkat kematangan 3,7. Dari nilai kematangan ini dapat disimpulkan bahwa kinerja sistem informasi pada Pengadilan Agama Tanjung Karang Kelas I A Bandar Lampung berada pada level Managed and Measureabel artinya organisasi telah memiliki sejumlah indikator atau ukuran kuantitatif yang dijadikan sebagai sasaran ataupun obyektif kinerja pada penerapan aplikasi teknologi informasi yang ada, karena organisasi memiliki kontrol terhadap proses teknologi informasi untuk mengurangi variasi kinerja proses sehingga proses pengembangan dapat ditentukan dengan limit yang dapat diukur namun harus dilakukan secara berhati-hati.

\subsection{Nilai Kesenjangan Kematangan Saat Ini (GAP)}

Berdasarkan nilai yang diketahui dari tingkat kematangan kinerja sistem informasi yaitu sebesar 3,7 akan dilakukan analisis kesenjangan terhadap tingkat kematangan yang diharapkan yaitu sebesar 5 . Hasil analisa ini diharapkan dapat memberikan kemudahan untuk meningkatkan proses kinerja sistem informasi sesuai dengan yang diharapkan. Alasan nilai yang ditargetkan 5 adalah melihat ketersediaan dan kesiapan kantor dalam bidang kinerja sistem informasi terkait aplikasi SIPP.

Tabel 4. Analisis Kesenjangan (GAP)

\begin{tabular}{|c|c|c|c|c|}
\hline \multirow{2}{*}{ No } & \multirow{2}{*}{ Proses } & \multicolumn{3}{|c|}{ Tingkat Kematangan } \\
\cline { 3 - 5 } & & Saat Ini & Diharapkan & GAP \\
\hline 1 & EDM03 & 3,4 & 5 & $5,0-3,4=1,6$ \\
\hline 2 & APO01 & 4,0 & 5 & $5,0-4,0=1,0$ \\
\hline 3 & APO011 & 3,6 & 5 & $5,0-3,6=1,4$ \\
\hline 4 & APO012 & 3,7 & 5 & $5,0-3,7=1,3$ \\
\hline 5 & BAI06 & 3,9 & 5 & $5,0-3,9=1,1$ \\
\hline 6 & DSS01 & 3,5 & 5 & $5,0-3,5=1,5$ \\
\hline 7 & DSS02 & 3,8 & 5 & $5,0-3,8=1,2$ \\
\hline 8 & DSS03 & 3,4 & 5 & $5,0-3,4=1,6$ \\
\hline 9 & DSS05 & 3,5 & 5 & $5,0-3,5=1,5$ \\
\hline 10 & MEA01 & 3,9 & 5 & $5,0-3,9=1,1$ \\
\hline 11 & MEA02 & 3,7 & 5 & $5,0-3,7=1,3$ \\
\hline \multicolumn{4}{|c|}{ Nilai Rata-rata } \\
\hline
\end{tabular}

Terdapat kesenjangan yaitu 1,3 pada proses domain EDM03, APO01, APO011, APO012, BAI06, DSS01, DSS02, DSS03, DSS05, MEA01, MEA02 antara nilai kematangan saat ini dengan nilai tingkat kematangan yang diharapkan. Meskipun GAP terbilang cukup kecil akan tetapi dibutuhkan penyesuaian masing-masing proses karena 1,3 merupakan nilai rata-rata per-proses, maka penulis akan memberikan rekomendasi pada masing-masing proses sehingga perbaikan dapat dilakukan secara menyeluruh peningkatan kinerja sistem informasi pada Pengadilan Agama Tanjung Karang Kelas I A Bandar Lampung.

Berdasarkan nilai perhitungan kesenjangan dari masing-masing proses diatas dapat disimpulkan pada gambar dibawah ini :

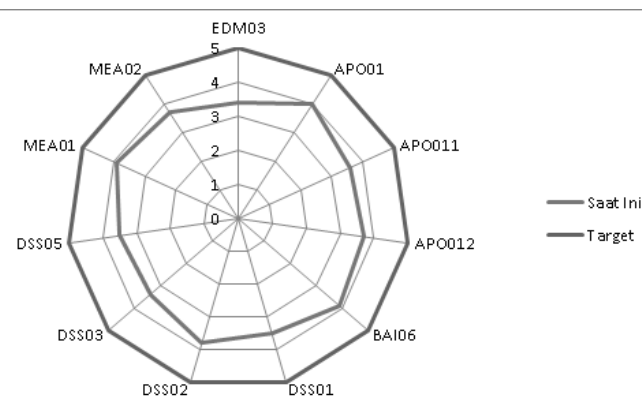

Gambar 3. Kesenjangan masing-masing proses 
Berdasarkan grafik diatas menjelaskan kesenjangan masing-masing proses dalam bentuk spider chart dengan memberikan kesimpulan yaitu ke 11 (kesebelas) proses dalam COBIT 5 terdapat 9 bagian yang dikategorikan ke Managed and Measureabel dan 2 bagian dikategorikan kedalam Defined Process.

\section{KESIMPULAN}

3.1 Simpulan

1. Menganalisis hasil penyebaran kuisioner dengan menghasilkan nilai rata-rata yaitu 3,7 dari nilai 0 sampai 5 pada domain EDM03, APO01, APO011, APO012, BAI06, DSS01, DSS02, DSS03, DSS05, MEA01 dan MEA02. Artinya Pengadilan Agama Tanjung Karang Kelas I A Bandar Lampung telah memiliki sejumlah indikator atau ukuran kuantitatif yang dijadikan sebagai sasaran ataupun obyektif kinerja pada penerapan aplikasi teknologi informasi yang ada, karena organisasi memiliki kontrol terhadap proses teknologi informasi untuk mengurangi variasi kinerja proses sehingga proses pengembangan dapat ditentukan dengan limit yang dapat diukur namun harus dilakukan secara berhati-hati.

2. Hasil evaluasi menemukan variasi antara kedua proses domain yang digunakan untuk menganalisis kinerja sistem informasi, dimana pada proses EDM03 dan DSS03 dikategorikan kedalam Defined Process kemudian untuk proses domain APO01, APO011, APO012, BAI06, DSS01, DSS02, DSS05, MEA01, dan MEA02 dikategorikan kedalam Managed and Measureabel.

\subsection{Saran}

Berdasarkan penelitian yang telah dilakukan penulis merekomendasikan saran yang nantinya dapat digunakan oleh Pengadilan Agama Tanjung Karang Kelas I A Bandar Lampung untuk meningkatkan kinerja sistem informasi sebagai landasan bagi penelitian selanjutnya yaitu dengan melakukan pengembangan sistem informasi penelusuran perkara secara rutin dan berhati-hati, serta melakukan monitoring terhadap aplikasi SIPP saat pengiriman data perkara ke pusat

\section{DAFTAR PUSTAKA}

[1] C.R. Khotari., 2004. New Age International (P) Ltd., Publisher. Research Methodology, Methods and Techniques, Jaipur.

[2] Hardcastle E. 2011. Business Information System. Bookboon.

[3] ICAI. 2010. Information System Control and Audit. New Delhi. India.

[4] ISACA. 2012. Kerangka COBIT 5, COBIT 4.1, BMI (Modelling Bussiness Information), Manajemen Tata Kelola, Jaminan Framework, Kerangka IT Risk, Major ISACA.

[5] ITGI 2007. COBIT 4.1. Rolling Meadow. IT Governance Institute USA.

[6] Kominfo. 2011. Panduan Tata Kelola Keamanan Informasi Bagi Penyelenggara Palayanan Publik, Direktorat Keamanan Informasi Kementerian Komunikasi dan Informatika RI.

.[7] Nugroho, Bagus Ariel dan Amiq Fahmi. 2015. Analisis Tiingkat Kapabilistas Sistem Informasi Rumah Sakit Berdasarkan COBIT 5 (MEA01) pada RSUD Tugurejo Semarang. Sistem Informasi Fakultas Ilmu Komputer Universitas Dian Nuswantoro Semarang, Semarang.

[8] Romney, Steintbart. 2015. Sistem Informasi, Jakarta.

[9] Schiller M. 2011. The MeGraw-Hill Copmaines, Audit TI Menggunakan Kontrol untuk Melindungi Asset Informasi, Amerika Serikat.

[10] Solehah, Nur Yulianti. 2016. Audit Tata Kelola Keamanan Informasi pada Kantor Wilayah Kementerian Agama Provinsi Lampung. Program Studi Sistem Informasi, Sekolah Tinggi Manajemen Informatika dan Komputer, Teknokrat, Bandar Lampung. 